\title{
HUBUNGAN DUKUNGAN KELUARGA DENGAN KEAKTIFAN LANSIA \\ DALAM MENGIKUTI KEGIATAN POSYANDU LANSIA \\ (Studi Puskesmas Kumpai Batu Atas Kecamatan Arut Selatan Kabupaten \\ Kotawaringin Barat Provinsi Kalimantan Tengah Tahun 2017)
}

\author{
Elis Agustina ${ }^{1}$ Rahaju Ningtyas $^{2}$ Eko Sari Ajiningtyas ${ }^{3}$ \\ ${ }^{123}$ STIKes Borneo Cendekia Medika Pangkalan Bun \\ 1email : elisagustina@gmail.com, 2email : ningtyasrahaju@gmail.com, 3email : \\ mahardikagunardi@gmail.com
}

\begin{abstract}
ABSTRAK
Pendahuluan :Keaktifan lansia mempunyai arti sama dengan aktivitas banyak sedikitnya orang yang menyatakan diri atau menjelmakan perasaan dan pikirian yang spontan ataupun sesorang yang memeliki kegiatan yang membuat seseorang tersebut sibuk. Dukungan keluarga adalah sikap tindakan seseorang kepeda anggota keluarganya berupa dukungan infomasional , dukungan penilaian, dikungan instrumental dan dukungan emosiaonal .Tujuan : penelitian ini untuk mengetahui hubungan dukungan keluarga dengan keaktifan lansia dalam mengikuti kegitan posyandu.Metode:Desain penelitian ini menggunakan desain diskriptip korelasi pada keluarga dan lansia di Puskesmas Kumpai Batu Atas tahun 2017 dengan sample berjumlah 96 lansia dengan teknik analisis bivariat dengan analisis distribusi frekuensi dan chi squre metode pengumpulan data menggunakan kuesioner kepada keluarga dan lansia .keluarga memberikan dukungan dalam keaktifa lansia sebanyak 75 orang $(78,1 \%)$ dan lansia yang tidak aktif dalam mengikuti kegiatan posyandu 55 orang $(57,3 \%)$ Hasil :Dengan hasil Uji chi squre menunjukan hasil 0,153 p >0,005 menggunakan aplikasi SPSS 16.Saran kepada petugas kesehatan dipuskesmas kumpai batu atas jika ada lansia yang tidak bisa hadir mengikuti kegiatan posyandu karena faktor fisik lansia yang lemah maka dapat dilakukan home care.Kesimpulan :Berdasarkan hal tersebut maka dapat disimpulkan bahwa tidak terdapat hubungan yang signifikan antara dukungan keluarga dengan keaktifan lansia dalam mengikuti kegiatan posyandu lansia di Puskesmas Kumpai Batu Atas.
\end{abstract}

Kata Kunci : Dukunggan keluarga, Keaktifan lansia, Posyandu.

FAMILY SUPPORT RELATIONSHIP WITH ELDERLY ACTIVITY IN

FOLLOWING INTEGRATED SERVICE CENTER ELDERLY ACTIVITIES

(Studies in Community Health Centers Stone Kumpai on Village District of Arut Selatan West Kotawaringin Central Borneo 2017)

\begin{abstract}
Introduction:The liveliness of the elderly has the same meaning as the activity of many at least people who claim themselves or manifest a spontaneous feelings and thoughts or someone who has activities that make someone busy. Family support is the attitude of a person's actions to family members in the form of infomational support, valuation support, instrumental support and emotional. Purpose:
\end{abstract}


support.The purpose of this research is to know the relationship of family support with elderly activeness in following the activity of integrated service center. Method :The design of this study used a correlation discriptip design on family and elderly at stone Kumpai on Community Service Center in 2017 with sample of 96 elderly with bivariate analysis technique with frequency distribution analysis and chi squre method of data collection using questionnaire to family and elderly. $75 \%(78,1 \%)$ elderly and elderly are not active in following posyandu activity 55 people $(57,3 \%)$ Result : With result of chi squre test showed result 0,153 p>0,005 using application of SPSS 16.Suggestion to health officer at community health center of high stone if there are elderly who can not attend integrated service center activity because of weak physical factor ofelderly hence can be done home care. ConclusionBased on this matter, it can be concluded that there is no significant relationship between family support and elderly activeness in following the posyandu elderly activity in Community Health Center Kumpai Batu Atas.

Keywords: Family support, liveliness of the elderly, integrated service center.

\section{PENDAHULUAN}

Lansia secara perlahan akan kegiatan posyandu sebanyak 126 orang atau setara dengan $17 \%$ dan yang aktif sebulan terakhir 66 orang atau setara $52 \%$.Berdasarkan hal tersebut maka ingin mengetahui lebih lanjut tentag hubungan dukungan keluarga dengan keaktifan lansia dalam mengikuti Kegiatan Posyandu Lansia Didesa Kumpai Batu Atas. Mengalami penurunan daya jaringan sehingga sering terserang penyakit. Penurunan daya atahan tubuh lansia akibat faktor usia maka dari itu lansia mudah terserang infeksi dan gangguan dari luar. (Padilla 2013,6 ). Menjadi tua adalah adah proses yang tidak dapat dihindari kita semua namun tidak berpengaruh dengan penilaian ciri menjadi tua. meningkatnya jumlah lansia setiap tahun di dunia maka akan berpengaruh dengan angka usia produktif.

Jumlah lansia di dunia menurut (WHO 2012 dalam Eka Fatmawati $2016,1)$ sudah mencapai $9,11 \%$, di Indonesia sendiri jumlah lansia berdesarkan data sensus nasional tahun 2014 mencapai 20,24 juta jiwa atau setara dengan $8,03 \%$ di Indoesia . Menurut BPS 2014 di kalimantan tengah jumlah penduduk mencapai 2.439 .858 jiwa sedangkan jumlah lansia nya hampir $20 \%$ dari jumlah penduduk 2.439.858 (Johansyah, 2015, 75).Menurut BPS Jumlah lansia di kotawaringin Barat penduduk tahun 2014 mencapai 269.926 jiwa sedangkan jumlah lansianya mencapai $15 \%$ dari 269.926 jumlah penduduk di kotawaringin barat Sedangkan lansia yang yang memanfaatkan pelayanan posyandu tahun 2010 sebanyak 63.311 sekitar $31,4 \%$ dari jumlah lansia. Berdasarkan data tahun 2015 jumlah lansia di desa kumpai batu atas 706 orang (Johansyah, 2015, 75). Berdasarkan hasil studi pendahuluan yang dilakukan pada hari rabu 26 April 2017 jumlah lansia di desa kumpai batu atas yang terdaftar mengikutikegiatan Posyandu Lansia Didesa Kumpai Batu Atas.

Tingginya angka ketidak aktifan lansia perlu diantisipasi, salah satunya dengan adanya dukungan 
keluarga. Dukungan keluarga merupakan suatu dorongan atau suatu penguat suatu keputusan yang diberikan oleh keluarga terhadap anggota keluarga dan dukungungan sosial yang diperlukan seseorang apabila anggota keluarga tersebaut sakit - (Hidayati 2002 dalam Handayani 2012 ,55 ).Kurangnya dukungan keluarga untuk mengantar atau sekedar mengingatkan lansia untuk mengikuti kegiatan posyandu petugas kesehatan atau kader posyandu yang kurang ramah dengan lansia juga dapat berpengaruh terhadap lansia aktif datang keposyandu karena banyak lansia yang mudah tersinggung dengan perkataan petugas kesehatan atau kader yang bertugas yang berbicara yang terlalu lantang akan membuat lansia tersinggung karena mereka merasa dibentak oleh petugas kesehatan. Dukungan sebagai penghargaan atau mendorong seseorang untuk lebih maju atau menolong orang denga sikap menerima kondisinya ,dukungan keluarga tersebut diperoleh dari individu ataupun kelompok dukungan sosial juga saat seorang mengalami masalah Efendi2009 dalam Handayani 2012 , 55).Dari jumlah angka ketidakaktifan lansia maka penulis ingin meneliti tentang Hubungan dukungan keluarga dengan keaktifan lansia dalam mengikuti kegiatan posyandu lansia di puskesmas desa kumpai batu atas Kab. Kotawarigin Barat.

\section{METODE PENELITIAN}

Metode penelitian ini menggunakan metode deskriptif korelasidan metode pendekatan yang digunkan dalam penelitian ini adalah metode pendekan cross sectional. Lokasi yang akan dilakukan penelitianDi Puskesmas Kumpai Batu Atas Kecamatan Arut Selatan Kabupaten Kotawaringin Barat. Populasi yang akan diteliti adalah Lansia seluruh lansia yang mengikuti kegiatan posyndu lansia di Puskesmas kumpai batu atas kec.arut selatan kab.kobar. Sampel yang digunkan pada penelitia ini adalah 96 orang lansia. Pengumpulan data pada penelitian ini menggunakan data primer dan data sekunder, data primer didapatkan dari hasil kuesioner yang dibagikan kepada lansia, data sekunder merupakan databyang diperoleh dari laporan data posyandu lansia dipuskesmas.

Analisa data yang digunakan analisa univariat dan bivariat. Instrumen yang digunakan untuk pengumpulan data adalah kuesioner yang berisi serangkaian pertanyaan yang mengacu pada variabel yang sudah diuji validasnya dan realibilitasnya .Aalisa data yang digunakan adalah uji chi square $a=0,05$.

\section{HASIL PENELITIAN}

\section{Data Umum}

Tabel 1 Distribusi frekuensi berdasarkan umur lansia yang mengikuti kegiatan posyandu lansia di Puskesmas Kumpai Batu Atas.

\begin{tabular}{ccc}
\hline Usia & Jumlah & Persentasi (\%) \\
\hline $45-59$ & 72 & 75,0 \\
$60-70$ & 22 & 22,9 \\
$71-80$ & 2 & 2,1 \\
\hline Total & 96 & 100 \\
\hline Sumber: Data Primer Mei 2017.
\end{tabular}

Berdasarkan hasil penelitian sebagian besar dari lansia yang mengikuti kegiatan posyandu di Puskesmas 
Kumpai Batu Atas memiliki usia 4559 tahun sebanyak 72 orang $(75 \%)$.

Tabel 2 Distribusi frekuensi berdasarkan pekerjaan lansia yang mengikuti kegiatan posyandu lansia di Puskesmas Kumpai Batu Atas.

\begin{tabular}{lcc}
\hline Pekerjaan & Jumlah & Persentase $(\%)$ \\
\hline Pekebun & 34 & 35,4 \\
Pegawai & 0 & 0 \\
Negeri & & \\
Pegawai & 9 & 9,4 \\
Swasta & & \\
Wiraswasta & 23 & 24,0 \\
Tidak & 30 & 31,2 \\
Bekerja & & \\
\hline \multicolumn{1}{c}{ Total } & 96 & 100 \\
\hline \multicolumn{2}{l}{ Sumber: Data Primer Mei 2017. }
\end{tabular}

Berdasarkan hasil penelitian bahwa hampir setengah lansia yang mengikuti kegiatan posyandu di puskesmas Kumpai Batu Atas bekerja sebagai pekebun sebanyak 34 orang $(35,4 \%)$.

Tabel 3 Distribusi frekuensi berdasarkan tinggal dirumah lansia yang mengikuti kegiatan posyandu lansia di Pusekesmas kumpai Batu Atas.

\begin{tabular}{|c|c|c|}
\hline $\begin{array}{c}\text { Tinggal } \\
\text { dirumah }\end{array}$ & Jumlah & Persentase $(\%)$ \\
\hline Suami & 50 & 52 \\
\hline Anak & 42 & 43,8 \\
\hline Sendiri & 4 & 4,2 \\
\hline Total & 96 & 100 \\
\hline
\end{tabular}

Berdasarkan hasil peneitian pada tabel 3 bahwa sebagian besar dari lansia yang mengikuti kegiatan posyandu di Puskesmas Kumpai Batu Atas tinggal bersama suami sebanyak 50 orang $(52 \%)$.

\section{Data khusus}

Tabel 4 peran keluarga dalam mendukung lansia untuk mengikuti kegiatan posyandu lansia di Puskesmas Kumpai Batu Atas.

\begin{tabular}{ccc}
\hline Dukungan & Frekuensi & $\begin{array}{c}\text { Persentas } \\
\mathrm{e}(\%)\end{array}$ \\
\hline Mendukung & 75 & 78,1 \\
$\begin{array}{c}\text { Kurang } \\
\text { mendukung }\end{array}$ & 21 & 21,9 \\
\hline Total & 96 & 100 \\
\hline
\end{tabular}

Sumber: Data Primer Mei 2017

Pada tabel Pada tabel diatas menunjukan bahwa hampir seluruh keluarga mendukung dengan kegiatan posyandu lansia di Puskesmas Kumpai Batu Atas sebanyak 75 orang( $78,1 \%)$.

Tabel 5 peran keaktifan lansia dalam mengikuti kegiatan posyandu lansia di Puskesmas Kumpai Batu Atas

\begin{tabular}{lll}
\hline Keaktifan & Frekuensi & Persentase \\
\hline Aktif & 40 & 42,7 \\
$\begin{array}{l}\text { Kurang } \\
\text { aktif }\end{array}$ & 56 & 57,3 \\
\hline Total & 96 & 100 \\
\hline
\end{tabular}

Pada tabel 5 diatas menunjukan bahwa sebagian besar dari lansia kurang aktif mengikuti kegiatan posyandu lansia di Puskesmas Kumpai Batau Atas sebanyak 56 orang $(60,4)$.

Tabel 6 Analisa Bivariat hubungan dukungan keluarga dengan keaktifan lansia dalam mengikuti kegiatan posyandu lansia di Puskesmas Kumpai Batu Atas. 


\begin{tabular}{|c|c|c|c|}
\hline & \multicolumn{2}{|c|}{ Keaktifan } & \multirow{2}{*}{ Total } \\
\hline & Aktif & Kurang aktif & \\
\hline \multirow{2}{*}{$\begin{array}{l}\text { Menduk } \\
\text { ung }\end{array}$} & 75 & 48 & 85 \\
\hline & $78,1 \%$ & $87,3 \%$ & $88,5 \%$ \\
\hline \multirow{2}{*}{$\begin{array}{c}\text { Kurang } \\
\text { menduk } \\
\text { ung }\end{array}$} & 21 & 7 & 11 \\
\hline & $21.9 \%$ & $12,7 \%$ & $11,5 \%$ \\
\hline \multirow{2}{*}{ Total } & 96 & 56 & 96 \\
\hline & $100 \%$ & $100 \%$ & $100 \%$ \\
\hline \multicolumn{4}{|c|}{ Uji chi squarep $=0,153$} \\
\hline
\end{tabular}

Sumber: Data Primer Mei 201

Berdasarkan hasil penghitungan uji statistik chi square dengan menggunakan aplikasi spss 16.0 for windows di dapatkan angka $\mathrm{p}$ value $=$ 0,153 . Apabila nilai alpha $(\alpha)=0,05$ maka nilai $p$ value $(0,000)>$ dari nilai alpha $(\alpha)(0,05)$ maka $\mathrm{H} 0$ di terima ,jadi tidak ada hubungan dukungan keluarga dengan keaktifan lansia dalam mengikuti kegiatan posyandu lasia di puskesmas kumpai batu atas.

\section{PEMBAHASAN}

\section{Dukugan keluarga}

Berdasarkan data yang ditunjukan pada tabel bahwa sebagian besar lansia yang mengikuti kegiatan posyandu lansia dikumpai batu atas memiliki umur 4559 sebanyak 72 orang $(78 \%, 1)$ lansia yang mengikuti kegiatan posyandu dengan umur yang sudah tidak muda lagi itu diharapkan lansia agar bisa lebih produktifatau sehat diusia senja. Menurut Padila $(2013,7)$. Sehat diusia senja merupakan kemampuan seseorang dalam menjalakan atau mengikuti kegiatan diusia yang tidak produktif. Berdasarakan tabel hampir setengah dari lansia yang mengikuti kegiatan posyandu bekerja sebagai pekebun sebanyak 34 orang $(35,4 \%)$. Berdasarkan tabel lansia yang mengikuti kegiatan posyandu bahwa sebagian tinggal bersama suami. Menurut hasil penelitian yang di tunjukkan pada tabel menyatakan bahwa hampir seluruh kelurga mendukung terhadap kegiatan

posyandu lansia dengan kriteria mendukung dan kurang mendukung, keluarga yang mendukung berjumlah 75 responden $(88,5 \%)$, hampir seluruh keluarga mendukung denganmemenuhi 5 indikator dukungan keluarga.Dukungan keluarga dapat mempengaruhi kenyamanan seseorang dimana seseorang tersebut merasa diperhatikan atau merasa dipedulikan dan dihargai apabila sesorang itu melakukan hal positif seperti mengikuti kegiatan posyandu. Menurut peneliti tingkat penegetahuan keluarga tentang kegiatan posyandu hampir seluruhnya mengetahuai akan pentingnya mengikuti kegiatan posyadu dan itu akan lebih mudah untuk meotivasi, memberikan dorongan atau informasi terhadap lansia untuk mengikuti kegiatan posyandu dibandingkan dengan keluarga yang kurang mendukung dengan kegiatan posyandu karena kurang mengetahui informasi atau manfaat apabila mengikuti kegiatan posyandu lansia, akan tetapi banyak lansia yang masih kurang aktif dalam mengikuti kegiatan posyandu karena sebagian besar lansia masih kurang pengetahuan lansia akan pentingnya manfaat posyandu berdasarkan tabulasi keaktifan lansia dengan indikator sebanyak 56 orang $(58,3 \%)$.Dukungan keluarga juga dapat memberikan nasihat atau sekedar informasi yang dapat membantu seseorang untuk lebih giat atau lebih termotivasi untuk melakukan suatu kegiatan ,dukungan keluarga sangat penting dan ditambah dengan dukungan sosial (Hidayati 2002 dalamHandayani 2012,55 ) Dukungan keluarga adalah dukungan yang terdiri 
dari informasi atau nasihat verbal atau nonverbal, bantuan nyata atau bantuan tindakan oleh keakraban sosial atau didapat karena kehadiran orang yang mendukung serta hal ini mempunyai manfaat emosional atau efek prilaku penerima selain itu penerima merasa dipedulikan dihargai atau dicintai. keaktifan lansia dalam mengikuti kegiatan posyandu lansia.

\section{Keaktifan Lansia Dalam Mengikuti Kegiatan Posyandu.}

Keaktifan Lansia Dalam Mengikuti Kegiatan Posyandu .Berdasarkan table keaktifan lansia dalam mengikuti kegiatan posyandu lansia menyatakan bahwa sebagian besar lansia masih kurang aktif dalam mengikuti kegiatan posyandu lansia dengan menggunakan kriteria aktif dan kurang aktif, lansia yang kurang aktif berjumlah 55 orang $(57,3)$. Keluarga dapat menajdi motivator yang kuat bagi lansia untuk mendampingi ataumengantarkankeposyandulansia,me ngingatkan lansia jika lupa jadwal dan berusaha membantu mengatasi segala permasalahan bersama lansia ( Erfandi 2008 dalam Evan Mahatma Suseno 2016,15 ). Sebagian besar lansia yang kurang aktif mengikuti kegiatan posyandu lansia mengalami hambatan atau faktor-faktor lain yang menyebabkan lansia kurang aktif mengikutikegiatan posyandu. Adapun hambatan lansia kurang aktif mengikuti kegiatan posyandu lansia dikarenakan lansia sakit atau lansia sedang berhalangan hadir dikarenakan bekerja ataupun lansia yang yang beranggapan tidak mengikuti kegiatan posyandu lebih baik berdiam diri dirumah lansia yang beranggapan seperti itu karena mereka malas dalam mengikuti kegiatan atau mereka yang tidak mengetahu akan pentingnyakegiatan posyandu lansia tersebut.. Kondisi fisik yang lemah akan membuat seseorang merasa tidak leluasa untuk memanfaatkan pelayanan kesehatan dan sarana prasarananya itu juga yang sering mempengaruhi keaktifan lansia dalam mengikuti kegiatan posyandu (Notoadmodjo 2007 dalam Christe Yohana Sianturi 2017,26 ).Keaktifan lansia juga berpengaruh dengan usia lansia yang mengikuti kegiatan posyandu. Berdasarkan tabel usia yang mengikuti kegiatan posyandu menunjukan bahwa sebagian besar memiliki umur 45-59 sebanyak 72 orang $(75 \%)$. Usia lansia yang masih produktif sebenarnya harus lah menjalani kegiatan yang positf agar dapat menikmati usia yang mudah terserang penyakit akibat peneurunan daya tahan tubuh seiring bertambahnya usia. Penurunan daya atahan tubuh lansia akibat faktor usia maka dari itu lansia mudah terserang infeksi dan gangguan dari luar ( Padilla, 2013, 6).Berdarakan table bahwa hampir dari setengah lansia bekerja sebagai pekebun sebanyak 34 orang $(35,4)$, lansia yang berkerja karena sudah terbiasa dengan hoby atau kegiatan rutin mereka dan malas untuk mengikuti kegiatan posyandu karena mereka tidak mau meninggalkan pekerjaannya.Sebenarnya diposyandu lansia juga mengadakan kegiatan agar lansia tidak bosan dalam mengikuti kegiatan posyandu seperti senam lansia. Banyak hal yang seharusnya yang dapat dilakukan agar dapat melalui usia senja dengan sehat yaitu sekedar berkumpul dengan komunitas yang diadakan diposyandu lansia atau mengikuti kegiatan senam lansia yang ada diposyandu tetapi banyak juga lansia yang bernggapan lebih baik dirumah ataupun lebih baiak bekerja dari pada mengikuti kegiatan posyandu, sehingga anggapananggapan tersebut akan menurunkan 
minat lansia untuk datang keposyandu lansia .Berdasarkan tabel tempat tinggal lansia menunjukan bahwa sebgian besar lansia tinggal bersama suami sebnayak 50 orang (52\%) lansia yang tinggal bersanma suami akan berpengaruh juga karena pengetahuan mereka yang sesama lansia juga terbatas karena kurangnya penegtahuan dan sering bersama keluarga yang lain untuk bertukar informasi . Pengetahuan yang salah satu tentang tujuan dan manfaat posyandu dapat menimbulkan salah persepsi yang akhirnya kunjungan keposyandu rendah

(Purnama 2010 dalam Suseno, 2012,3).

\section{Hubungan dukungan keluarga dengan keaktifan lansia dalam mengikuti kegiatan posyandu lansia}

Berdasarkan tabel hampir seluruh keluarga mendukung dengan kegiatan posyandu lansia sebanyak 75 orang $(78,1 \%)$.Berdasarkan tabel 5.5 sebagian besar lansia masih kurang aktif sebnyak 55 orang $(57,3 \%)$ Berdasarkan tabel 5.6 menunjukan tidak ada hubungan dukungan keluarga dengan keaktifan lansia dalam mengikuti kegiatan posyandu lansia hal ini dibuktikan dengan dengan uji statistik chi squre dengan nilai signifikasi $\rho=, 153$, hal ini bisa terjadi karena keaktifan lansia dipengaruhi dengan faktor- faktor lain yang menyebabkan lansia tidak aktif mengikuti kegiatan posyandu lansia seperti faktor fisik lansia, pengetahuan lansia, informasi posyandu lansia yang tidak didpat kannya sehingga lansia tidak dapat mengikuti kegiatan posyandu lansia saja lansia yang tidak aktif disebabkan faktor lain seperti fisik yang lemah atau pengetahuan lansia yang kurang, maka lansia tersebut tidak dapat mengikuti kegiataan posyandu lansia. Pengetahuan lansia yang rendah juga mempengaruhi keaktifan lansia karena mereka tidak mengetahui atau mengerti tentang posyandu lansia berdasarkan tabulasi keaktifan lansia yang terlampir dengan indikator pengetahuan, hanya sebagian kecil dari lansia mengetahui tentang posyandu lansia sebanyak( $21,16 \%)$. Kondisi fisik yang lemah akan membuat seseorang merasa tidak leluasa untuk memanfaatkan pelayanan kesehatan dan sarana prasarananya itu juga yang sering mempengaruhi keaktifan lansia dalam mengikuti kegiatan posyandu (Notoadmodjo 2007 dalam Christe Yohana Sianturi ,2017,25).

\section{KESIMPULAN DAN SARAN}

\section{Kesimpulan}

1. Keluarga mendukung terhadap lansia dalam mengikuti kegiatan posyandu lansia di Puskesmas Kumpai Batu Atas

2. keaktifan lansia dalam mengahadiri kegiatan posyandu masih kurang walaupun keluarga mendukung lansia kurang aktif mengahdari kegiatan posyandu

3. Tidak ada hubugan dukungan keluarga dengan keaktifan lansia dalam mengikuti kegiatan posyandu lansia. di puskesmas kumpai batu atas.

\section{Saran}

1. Bagi Institusi pendidikan Sebagai tinjauan keilmuan dan menambah referensi keperawatan gerontik di STIkes ICME Jombang

2. Bagi tenaga kesehatan di puskesmas kumpai batu atas Tenaga kesehatan di harapkan memberi pujian atau semangat 
kepada lansia agar lebih rajin aktif lagi untuk mengikuti kegiatan posyandu lansia .

3. Bagi Tempat penelitian di Puskesmas Kumpai Batu Atas

Diharapkan bisa lebihditingkatkandenganmemb erikan keiatan yang tidak yang bervariasi lagi agar lansia lebih banyak yang aktif untuk mengikuti kegiatan posyandu.

4. Bagi Lansia Di Puskesmas Kumpai Batu Atas

Bagi lansia agar lebih ditingkatkan lagi keaktifan nya dalam mengikuti kegiatan posyandu lansia untuk keshatan diusia senja.

5. Peneliti Selanjutnya

Melakukan penelitian tentang faktor yang mempengaruhi keaktifan lasia dalam menghadiri kegiatan posyandu lansia .

\section{DAFTAR PUSTAKA}

Fatmawati Eka 2016Hubungan Tingkat Pengetahuan Tentang Posyandu Lansia Dengan Motivasi Lansia Usia 60-74 Tahun Dalam Melakukan Kunjungan Keposyandu Lansia di posyandu lansia rw 04 desa teryang kecamatan sumber pucung kabupaten malang

Handayani, d. 2012. Hubungan Dukungan Keluarga Dengan Kepatuhan Lansia dalam mengikuti posyandu lansia di posyandu lansia Jetis Desa Karjan Kecamatan Weru Kabupaten Sukoharjo .
Johansyah ,basuki ,dkk, R.2011.statistik daerah kabupaten kotawaringin barat .Badan statistik kotawariingin barat .

Kresnawati.2011 .Hubungan Dukungan Keluarga Dengan Keaktifan Lansia Dalam Mengikuti Kegiatan Posyandu Lansia desa Gonilan Kecamatan Kartasura.

Mahatma Suseno Evan 2016 Hubungan Antara Persepsi Kegiatan Posyandu Lansia Dan Keluhan Fisik Terhadap Keaktifan Lansia Dalam Mengikuti Posyandu Lansia Di Desa Lengkeng Kecamatan Bulu Sukoharjo

Padila 2013Buku Ajar Keperawatan Gerontik

$\begin{array}{lrr}\text { Sianturi } & \text { Christe } & \text { Yohana } \\ \text { 2017Hubungan } & \text { Dukungan } \\ \text { Keluarga } & \text { Dengan } & \text { Faktor } \\ \text { Lainnya } & \text { Dengan } & \text { Keaktifan } \\ \text { Lansia } & \text { Dalam } & \text { Mengikuti } \\ \text { Kegiatan } & \text { Posyandu } & \text { Lansia } \\ \text { Diwilayah } & \text { Keja } & \text { Puskesmas } \\ \text { Rajabasa Indah. }\end{array}$

Suseno Mahara Dian 2016FaktorFaktor Yang Mempengaruhi Keaktifan Lansia Dalam Mengikuti Kegiatan Posyandu Lansia Di Desa Kauman Kecamtan Polanharjo Kabpaten Kalten 